Journal of Advanced Research in Fluid Mechanics and Thermal Sciences

\title{
Numerical Solution of Stagnation Point Flow and Heat Transfer over a Nonlinear Stretching/Shrinking Sheet in Hybrid Nanofluid: Stability Analysis
}

\author{
Nur Syazana Anuar ${ }^{1,}$, Norfifah Bachok $^{1,2}$, Norihan Md Arifin $^{1,2}$, Haliza Rosali $^{1}$ \\ Department of Mathematics, Faculty of Science, Universiti Putra Malaysia, 43400 Selangor, Malaysia \\ Institute for Mathematical Research, Universiti Putra Malaysia, 43400 Selangor, Malaysia
}

\section{ARTICLE INFO ABSTRACT}

\section{Article history:}

Received 17 May 2020

Received in revised form 25 August 2020

Accepted 3 September 2020

Available online 17 October 2020

\begin{abstract}
The steady, laminar, stagnation point flow of hybrid nanofluid past a nonlinearly stretching and shrinking sheet is studied. Hybrid nanofluid is regarded by disseminated two distinct nano-sized particles, silver $(\mathrm{Ag})$ and copper oxide $(\mathrm{CuO})$ in pure water. Similarity technique was used for the transformation of partial differential equations (PDEs) into an ordinary differential equations (ODEs). Obtained ODEs were solved using Matlab's built in function (bvp4c). The results of important governing parameters which are nonlinear parameter, stretching/shrinking parameter and nanoparticle volume fraction are evaluated and discussed in graphical and tabular form for the velocity and temperature profiles, along with local skin friction, local Nusselt number. Nonunique solutions (first and second branch) are visible for some limit of shrinking parameter. It is noticed that nonlinear parameter hastens flow separations. Hence, a stability analysis is executed to identify which solutions are stable and physically feasible.
\end{abstract}

Keywords:

Hybrid nanofluid; onlinear

stretching/shrinking; stagnation point;

stability analysis

Copyright $@ 2020$ PENERBIT AKADEMIA BARU - All rights reserved

\section{Introduction}

Nanofluids are defined as a mixture containing nanoparticles smaller than micro-sized particles and base fluid that could significantly increase the thermal conductivity [1]. Nanofluids are found to have a high level of heat transfer properties than the normal fluids and the use of nanoparticles itself can enhance the fluid's thermophysical properties. However, the thermal conductivity increases more than ever even with the lower number of nanoparticles [2]. Suresh et al., [3] and Momin [4] have been conducted an experimental investigation on strengthening the base fluid's thermal conductivity. They found that the principle fluid's heat capacity enhanced when the mixture of two different nanoparticles disseminated in a base fluid which are known as hybrid nanofluids. For

\footnotetext{
* Corresponding author.

E-mail address: nursyazana931@gmail.com
}

https://doi.org/10.37934/arfmts.76.2.8598 
example, Aluminium oxide demonstrates more chemical inertness and stability, but has lower thermal conductivity compared to metallic nanoparticles. Furthermore, nanoparticles like zinc, copper and aluminium offers elevated thermal conductivities. Hybrid nanofluid have many engineering applications such as micro fluidics, nuclear safety, military, manufacturing, pharmaceutical, transportation and many more.

The above-mentioned facts on applications of hybrid nanofluids have attracted the interest of many authors to focus their studies on heat transfer characteristics through hybrid nanofluid. Devi and Devi [5] were the first who investigated a stretching surface using a boundary layer theory in hybrid nanofluid with Newtonian heating numerically. Furthermore, Hayat and Nadeem [6] discovered that the rate of cooling for hybrid nanofluid is greater compared to nanofluid with the existence of radiative heat generation and chemical reaction. Very recently, the hybrid nanofluid's flow due to variable viscosity and its heat transfer enhancement on natural convection were numerically analysed by Manjunatha et al., [7]. Also, many researchers have shown an interest in hybrid nanofluids in their work [8-11].

Heat transfer characteristic and flow of a stretching/shrinking surface have been the subject of intensive study due to its applications in the industrial sector such as in the wire drawing, extraction of polymer sheets, glass-fibre production and paper production. The flow along a shrinking sheet in the stagnation region was investigated by Wang [12] and concluded that for larger shrinking rates, solutions do not exist. Afterward, Bachok et al., [13] extend the work of [12] to shrinking sheet along with the effect of melting heat transfer. Later, Bhattacharyya [14] considered the effect of chemical reaction on his study. The same observations are made with previous researchers where duality exists for the case of shrinking sheet. Some excellent reviews on flow cause by a stretching/shrinking surface can be found in the literature [15-17].

Vajravelu [18] develop the first study on the flow of nonlinear stretching sheet in viscous fluid. Afterward, Cortell [19] extended the problem of nonlinear shrinking sheet by considered it using two different types of thermal boundary conditions, i.e, prescribed and constant surface temperature. The nonlinear vertical stretching surface with varying fluid properties have been investigated by Prasad et al., [20]. Meanwhile, the case of nonlinear shrinking surface in nanofluid was studied by Rana and Bhargava [21]. Later, Zaimi et al., [22] analyzed the problem in stretching and shrinking surface respectively. The nonlinear shrinking sheet with slip impact in the stagnation region was studied by Fauzi et al., [23]. Rana et al., [24] explored the radiative nanofluid's flow over a nonlinear surface with suction and slip. A different aspect of such problems had been conducted by different authors [25-29].

The main idea of this study is to explore a hybrid nanofluid's flow in a nonlinearly stretching and shrinking surface. This study is an extended work from Bachok and Ishak by considering it in hybrid nanofluid. The governing equations were transformed using similarity variables into an ODEs which later be solved numerically using the Matlab's built in function (bvp4c). Since nonunique solutions are obtained, the stability of solutions is executed to test which solution is stable. The procedure to validate which solutions are stable was first proposed by Merkin [30]. More studies regarding stability analysis on boundary layer can be found in the literature [31-37]. Here, this analysis was implemented in order to investigate the growth of disturbances for first and second solutions. Stable solution indicates by the existence of initial decay of disruption, meanwhile, the solution with initial growth of disruption represents the unstable solution. 


\section{Mathematical Modeling}

A steady hybrid nanofluid's flow in a nonlinearly stretching and shrinking surface in the stagnation point region is investigated. The schematic illustration of the problem is shown in Figure 1 with $x-$ axis measures along the shrinking sheet in the vertical direction and $y$-axis is normal to it. The surface is assumed to stretch/shrink with the velocity $U_{w}(x)=a x^{n}$, given that $a>0$ is a constant flow and $U_{\infty}(x)=b x^{n}$ is the external (inviscid) fluid's velocity with $b>0$ being the stagnation-point's strength. The surface is remained at constant temperature $T_{w}$ and the temperature of ambient is $T_{\infty}$.

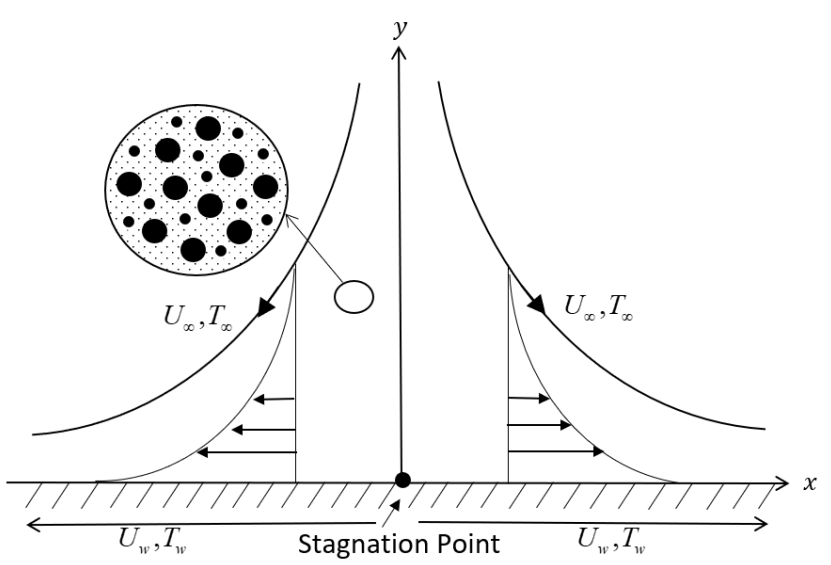

(a) Stretching

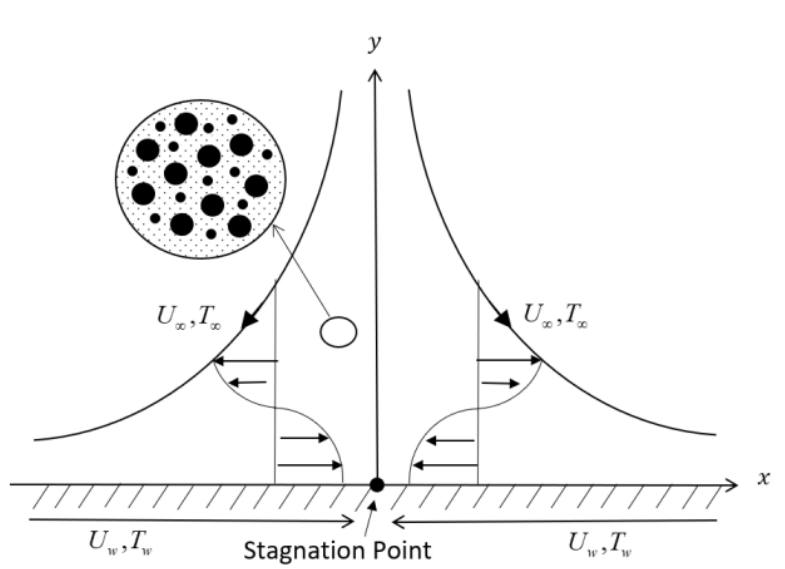

(b) Shrinking

Fig. 1. Schematic illustration of the flow

The governing equations can be written as $[16,37]$

$$
\frac{\partial u}{\partial x}+\frac{\partial v}{\partial y}=0
$$

$u \frac{\partial u}{\partial x}+v \frac{\partial u}{\partial y}=U_{\infty} \frac{d U_{\infty}}{d x}+\frac{\mu_{h n f}}{\rho_{h n f}} \frac{\partial^{2} u}{\partial y^{2}}$

$u \frac{\partial T}{\partial x}+v \frac{\partial T}{\partial y}=\alpha_{h n f} \frac{\partial^{2} T}{\partial y^{2}}$

together with conditions

$$
\begin{gathered}
v=0, \quad u=U_{w}(x), \quad T=T_{w} \quad \text { at } \quad y=0, \\
u \rightarrow U_{\infty}(x), \quad T \rightarrow T_{\infty} \quad \text { as } \quad y \rightarrow \infty,
\end{gathered}
$$

given that the velocity components, $u, v$ are in the $x$ and $y$ directions, respectively, $\rho_{\text {hnf }}, \mu_{\text {hnf }}$ and $\alpha_{h n f}$ is the hybrid nanofluid's density, dynamic viscosity and thermal diffusivity which are given by [5] 


$$
\begin{gathered}
\alpha_{h n f}=\frac{k_{h n f}}{\left(\rho C_{p}\right)_{h n f}}, \quad \rho_{h n f}=\varphi_{2} \rho_{s 2}+\left(1-\varphi_{2}\right)\left[\left(1-\varphi_{1}\right) \rho_{f}+\varphi_{1} \rho_{s 1}\right], \quad \mu_{h n f}=\frac{\mu_{f}}{\left(1-\varphi_{1}\right)^{2.5}\left(1-\varphi_{2}\right)^{2.5}}, \\
\frac{k_{h n f}}{k_{b f}}=\frac{k_{s 2}+2 k_{b f}-2 \varphi_{2}\left(k_{b f}-k_{s 2}\right)}{k_{s 2}+2 k_{b f}+\varphi_{2}\left(k_{b f}-k_{s 2}\right)} \quad \text { where } \frac{k_{b f}}{k_{f}}=\frac{2 k_{f}+k_{s 1}-2 \varphi_{1}\left(k_{f}-k_{s 1}\right)}{2 k_{f}+k_{s 1}+\varphi_{1}\left(k_{f}-k_{s 1}\right)} \\
\left(\rho C_{p}\right)_{h n f}=\varphi_{2}\left(\rho C_{p}\right)_{s 2}+\left(1-\varphi_{2}\right)\left[\left(1-\varphi_{1}\right)\left(\rho C_{p}\right)_{f}+\varphi_{1}\left(\rho C_{p}\right)_{s 1}\right] .
\end{gathered}
$$

Here, $\varphi_{1}$ is the CuO nanoparticle, $\varphi_{2}$ is the Ag nanoparticle, $\left(\rho C_{p}\right)$ and $k$ is the heat capacity and thermal conductivity given that the subscript ' $f$ ', ' $h n f$ ', ' $s 1$ ' and ' $s 2$ ' represent 'fluid', 'hybrid nanofluid', 'CuO nanoparticle' and 'Ag nanoparticle', respectively. Further, we introduced the following similarity transformation [38]

$\eta=\left(\frac{(n+1) b}{2 v_{f}}\right)^{1 / 2} y x^{\frac{n-1}{2}}, \quad \psi=\left(\frac{2 b v_{f}}{n+1}\right)^{1 / 2} x^{\frac{n+1}{2}} f(\eta), \quad T=\left(T_{w}-T_{\infty}\right) \theta(\eta)+T_{\infty}$

where the similarity variable is denotes by $\eta, \psi$ is the stream function and $v_{f}$ is the kinematic viscosity. The velocity components are defined as $v=-\frac{\partial \psi}{\partial x}$ and $u=\frac{\partial \psi}{\partial y}$. By using the defining parameter, Eq. (1) is fulfilled and the remaining Eq. (2)-(3) are transformed as follow

$$
\begin{aligned}
& \frac{\mu_{h n f} / \mu_{f}}{\rho_{h n f} / \rho_{f}} f^{\prime \prime \prime}+f f^{\prime \prime}-\left(\frac{2 n}{n+1}\right)\left(f^{\prime 2}+1\right)=0, \\
& \frac{k_{h n f} / k_{f}}{\left(\rho C_{p}\right)_{h n f} /\left(\rho C_{p}\right)_{f}} \frac{1}{\operatorname{Pr}} \theta^{\prime \prime}+f \theta^{\prime}=0,
\end{aligned}
$$

along with the conditions

$$
\begin{gathered}
f(0)=0, \quad \theta(0)=1, \quad f^{\prime}(0)=\varepsilon, \\
f^{\prime}(\eta) \rightarrow 1, \quad \theta(\eta) \rightarrow 0 \quad \text { as } \quad \eta \rightarrow \infty
\end{gathered}
$$

where prime signify the derivative with respect to $\eta$. The stretching and shrinking parameter denoted by $\varepsilon=b / a$ where the positive value represents stretching and negative value indicates shrinking. Prandtl number is given by $\operatorname{Pr}=v / \alpha$. We notice that, in the case of $n=1$ and $\varphi_{1}=\varphi_{2}=0$, Eq. (7) and (8) reduces to the boundary value problems in Bachok et al., [39].

The local skin friction is

$$
C_{f}=\frac{\tau_{w}}{\rho_{f} U_{\infty}^{2}} \quad \text { and } \quad \tau_{w}=\mu_{h n f}\left(\frac{\partial u}{\partial y}\right)_{y=0}
$$


while the local Nusselt number is

$N u_{x}=\frac{x q_{w}}{k_{f}\left(T_{w}-T_{\infty}\right)}$ and $q_{w}=-k_{h n f}\left(\frac{\partial T}{\partial y}\right)_{y=0}$.

Therefore, the above physical quantities are written as

$\operatorname{Re}_{x}^{1 / 2} C_{f}=\frac{\mu_{h n f}}{\mu_{f}} \sqrt{\frac{n+1}{2}} f^{\prime \prime}(0), \quad \operatorname{Re}_{x}^{-1 / 2} N u_{x}=-\frac{k_{h n f}}{k_{f}} \sqrt{\frac{n+1}{2}} \theta^{\prime}(0)$,

here, $\operatorname{Re}_{x}$ is the local Reynold number given by $U_{\infty} x / v_{f}$.

\section{Stability of Solutions}

To execute the stability of the solutions on the present problem, we need to consider the unsteady flow of our governing model [30]. Eq. (1) remains, meanwhile Eq. (2) and (3) replaced by as follows

$$
\begin{aligned}
& \frac{\partial u}{\partial t}+u \frac{\partial u}{\partial x}+v \frac{\partial u}{\partial y}=U_{\infty} \frac{d U_{\infty}}{d x}+\frac{\mu_{h n f}}{\rho_{h n f}} \frac{\partial^{2} u}{\partial y^{2}}, \\
& \frac{\partial T}{\partial t}+u \frac{\partial T}{\partial x}+v \frac{\partial T}{\partial y}=\alpha_{h n f} \frac{\partial^{2} T}{\partial y^{2}}
\end{aligned}
$$

along with the conditions

$$
\begin{gathered}
v=0, \quad u=U_{w}(x), \quad T=T_{w} \quad \text { at } \quad y=0, \\
u \rightarrow U_{\infty}(x), \quad T \rightarrow T_{\infty} \quad \text { as } \quad y \rightarrow \infty,
\end{gathered}
$$

the new similarity variables and dimensionless time variable $\tau$ are introduced, hence Eq. (7) can be replaced by

$\eta=\left(\frac{(n+1) b}{2 v_{f}}\right)^{1 / 2} y x^{\frac{n-1}{2}}, \psi=\left(\frac{2 b v_{f}}{n+1}\right)^{1 / 2} x^{\frac{n+1}{2}} f(\eta, \tau), T=\left(T_{w}-T_{\infty}\right) \theta(\eta, \tau)+T_{\infty}, \tau=b n x^{n-1} t$

the governing Eq. (13) and (14) become

$$
\begin{aligned}
& \frac{\mu_{h n f} / \mu_{f}}{\rho_{h n f} / \rho_{f}} \frac{\partial^{3} f}{\partial \eta^{3}}+f \frac{\partial^{2} f}{\partial \eta^{2}}+\left(\frac{2 n}{n+1}\right)\left(1-\left(\frac{\partial f}{\partial \eta}\right)^{2}-\frac{\partial^{2} f}{\partial \eta \partial \tau}\right)+2\left(\frac{n-1}{n+1}\right) \tau\left(\frac{\partial f}{\partial \tau} \frac{\partial^{2} f}{\partial \eta^{2}}-\frac{\partial f}{\partial \eta} \frac{\partial^{2} f}{\partial \eta \partial \tau}\right)=0, \\
& \frac{k_{h n f} / k_{f}}{\left(\rho C_{p}\right)_{h n f} /\left(\rho C_{p}\right)_{f}} \frac{1}{\operatorname{Pr}} \frac{\partial^{2} \theta}{\partial \eta^{2}}+f \frac{\partial \theta}{\partial \eta}-\left(\frac{2 n}{n+1}\right) \frac{\partial \theta}{\partial \tau}+2\left(\frac{n-1}{n+1}\right) \tau\left(\frac{\partial f}{\partial \tau} \frac{\partial \theta}{\partial \eta}-\frac{\partial f}{\partial \eta} \frac{\partial \theta}{\partial \tau}\right)=0,
\end{aligned}
$$


with conditions

$$
\begin{gathered}
f(0, \tau)=0, \quad \theta(0, \tau)=1, \quad \frac{\partial f}{\partial \eta}(0, \tau)=\varepsilon, \\
\frac{\partial f}{\partial \eta}(\eta, \tau) \rightarrow 1, \quad \theta(\eta, \tau) \rightarrow 0 \quad \text { as } \quad \eta \rightarrow \infty
\end{gathered}
$$

To specify the stability of the solution $f=f_{0}(\eta)$ and $\theta=\theta_{0}(\eta)$ satisfying Eq. (7)-(9), we write

$$
f(\eta, \tau)=f_{0}(\eta)+e^{-\gamma \tau} H(\eta, \tau), \quad \theta(\eta, \tau)=\theta_{0}(\eta)+e^{-\gamma \tau} G(\eta, \tau),
$$

here, eigenvalue parameter denoted by $\gamma, H(\eta, \tau)$ and $G(\eta, \tau)$ are relatively small than $f_{0}(\eta)$ and $\theta_{0}(\eta)$. Substitute Eq. (20) into Eq. (17)-(18), and take $\tau=0$, the following equations are obtained

$$
\begin{aligned}
& \frac{\mu_{h n f} / \mu_{f}}{\rho_{h n f} / \rho_{f}} H_{0}^{\prime \prime \prime}+H_{0} f_{0}^{\prime \prime}+f_{0} H_{0}^{\prime \prime}+\left(\frac{2 n}{n+1}\right)\left(-2 f_{0}^{\prime}+\gamma\right) H_{0}^{\prime}=0, \\
& \frac{k_{h n f} / k_{f}}{\left(\rho C_{p}\right)_{h n f} /\left(\rho C_{p}\right)_{f}} \frac{1}{\operatorname{Pr}} G_{0}^{\prime \prime}+f_{0} G_{0}^{\prime}+H_{0} \theta_{0}^{\prime}+\left(\frac{2 n}{n+1}\right) \gamma G_{0}=0,
\end{aligned}
$$

subject to conditions

$$
\begin{gathered}
H_{0}(0)=0, \quad G_{0}(0)=0, \quad H_{0}^{\prime}(0)=0 \\
H_{0}^{\prime}(\eta) \rightarrow 0, \quad G_{0}(\eta) \rightarrow 0 \quad \text { as } \quad \eta \rightarrow \infty
\end{gathered}
$$

Following the previous study [33], the bounds of eigenvalues $\gamma_{1}<\gamma_{2}<\gamma_{3}<\ldots$ can be dictated by relaxing $H_{0}^{\prime}(\eta) \rightarrow 0$ as $\eta \rightarrow \infty$ to a new boundary condition $H_{0}^{\prime \prime}(0)=1$. The system of Eq. (21) and (22) associated with conditions (23) are solved.

\section{Result and Discussions}

The numerical results are obtained by solving the ODEs (7) and (8) governs by the conditions (9) using the bvp4c solver in Matlab for different governing parameters such as $\mathrm{CuO}$ nanoparticle $\varphi_{1}, \mathrm{Ag}$ nanoparticle $\varphi_{2}$, nonlinear parameter $n$ and stretching/shrinking parameter $\varepsilon$. Initially, 0.1 volume fraction of $\mathrm{CuO}$ nanoparticle is disseminated into water to produce CuO-water nanofluid. The targeted '( $\mathrm{Ag}-\mathrm{CuO} /$ water) hybrid nanofluid' is therefore developed by dispersing silver nanoparticles in nanofluid (CuO-water) with different volume fractions. Pr is fixed to 6.2 which represent water and the quantity of nanoparticle volume fractions ranges from 0 to 0.2 [40]. The basic properties of nanoparticle and base fluid are illustrated in Table 1 . The present results of $f^{\prime \prime}(0)$ and $-\theta^{\prime}(0)$ have been validate with the previously reported result by Bachok et al., [39] as appeared in Table 2. The 
comparison values are in excellent accordance and we are therefore very assured that the numerical findings acquired are precise.

Table 1

Thermophysical properties of nanoparticle [8]

\begin{tabular}{llll}
\hline Properties & $\mathrm{Ag}$ & $\mathrm{CuO}$ & Base fluid (water) \\
\hline$\rho\left(\mathrm{kg} \mathrm{m}^{-3}\right)$ & 10500 & 6320 & 997.1 \\
$k\left(\mathrm{Wm}^{-1} \mathrm{~K}^{-1}\right)$ & 429 & 76.50 & 0.613 \\
$C_{p}\left(\mathrm{~J} \mathrm{~kg}^{-1} \mathrm{~K}^{-1}\right)$ & 235 & 531.80 & 4179 \\
\hline
\end{tabular}

Table 2

\begin{tabular}{llll}
\multicolumn{4}{l}{$f^{\prime \prime}(0)$ and $-\theta^{\prime}(0)$ when $\varphi_{1}=\varphi_{2}=0, n=1, \operatorname{Pr}=0.7$ and $\varepsilon=-1.1$} \\
\hline \multicolumn{4}{l}{ Bachok and Ishak } \\
\hline$f^{\prime \prime}(0)$ & $-\theta^{\prime}(0)$ & $f^{\prime \prime}(0)$ & $-\theta^{\prime}(0)$ \\
1.1867 & 0.1828 & 1.18668 & 0.18283 \\
{$[0.0492]$} & {$[0.0003]$} & {$[0.04923]$} & {$[0.00008]$} \\
\hline
\end{tabular}

"[]" second solution

Figure 2 and 3 are constructed to present the influence of $\mathrm{Ag}$ nanoparticle $\varphi_{2}$ on the velocity $f^{\prime}(\eta)$ and temperature $\theta(\eta)$ profiles for shrinking case. It is discovered that $f^{\prime}(\eta)$ increases considerably within the momentum boundary layer when $\mathrm{Ag}$ nanoparticle $\varphi_{2}$ increases from 0 to 0.2 for first and second solutions. This indicates that the existence of nanoparticles causing the thinning of the boundary layer. Further, $\theta(\eta)$ decreases with Ag nanoparticle $\varphi_{2}$ for both solutions and therefore, decreases the thermal boundary layer thickness. It is evident that duality exist when $\varepsilon=-1.2$. The graphical results in the reduced skin friction $f^{\prime \prime}(0)$ and reduced heat transfer $-\theta^{\prime}(0)$ with $\varepsilon$ for different values of $\mathrm{Ag}$ nanoparticle are illustrated in Figure 4 and 5 . It is observed that duality exists when $\varepsilon \leq-1$ and a unique solution exist when $\varepsilon>-1$. We noticed that there is no solution exist when $\varepsilon<\varepsilon_{c}$ because of the boundary layer separations are bound to happen and the boundary layer approximation are not possible beyond this critical values $\varepsilon_{c}$. In addition, the magnitude of $f^{\prime \prime}(0)$ are enhanced with an increasing of $\varphi_{2}$. Meanwhile, the increasing of $\varphi_{2}$ leads to decreasing values of $-\theta^{\prime}(0)$ when $\varepsilon>-0.5$ and opposite trait are observed when $\varepsilon<-0.5$. This is due to the fact that the insertion of nanoparticles in the base fluid will accelerate the fluid motion because of the collision between the base fluid particle and nanoparticles. Thus, decreasing the momentum and thermal boundary layer thickness and consequently, increases its skin frictions and heat transfer at the surface. 


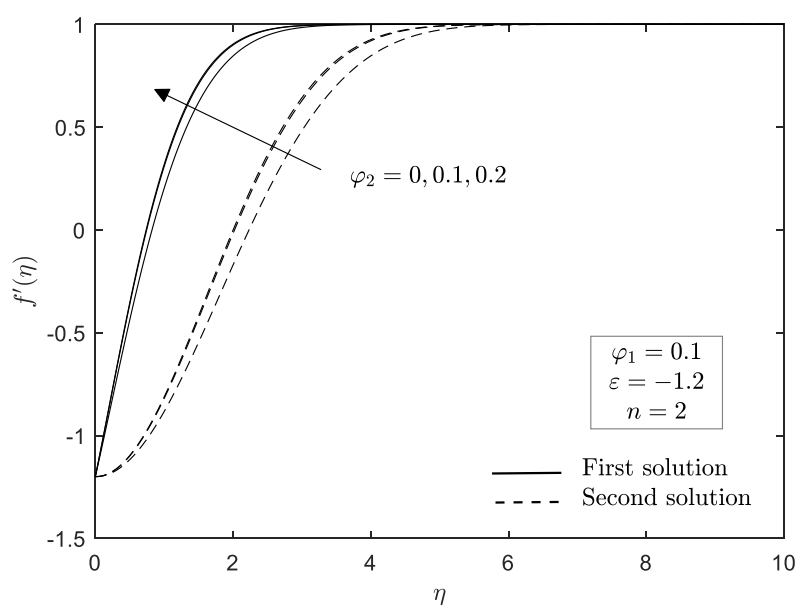

Fig. 2. Velocity profile for different $\varphi_{2}$

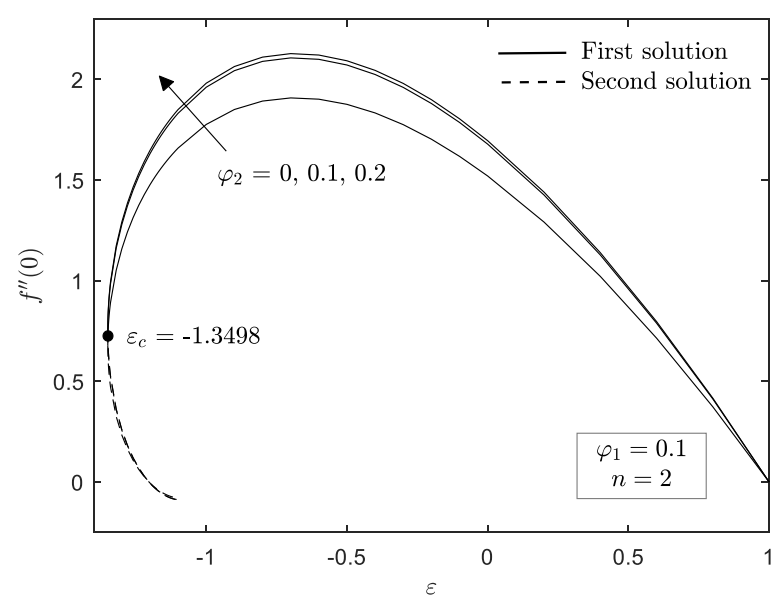

Fig. 4. $f^{\prime \prime}(0)$ with $\varepsilon$ for different $\varphi_{2}$

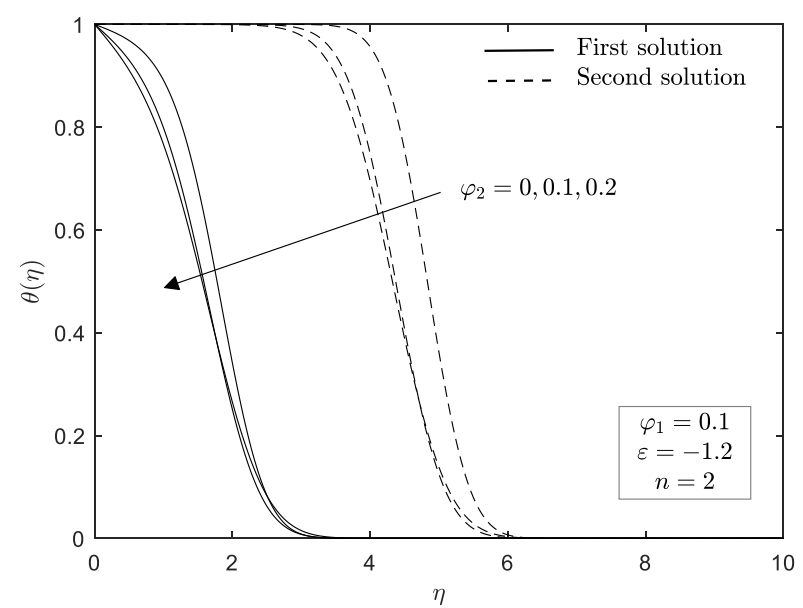

Fig. 3. Temperature profile for different $\varphi_{2}$

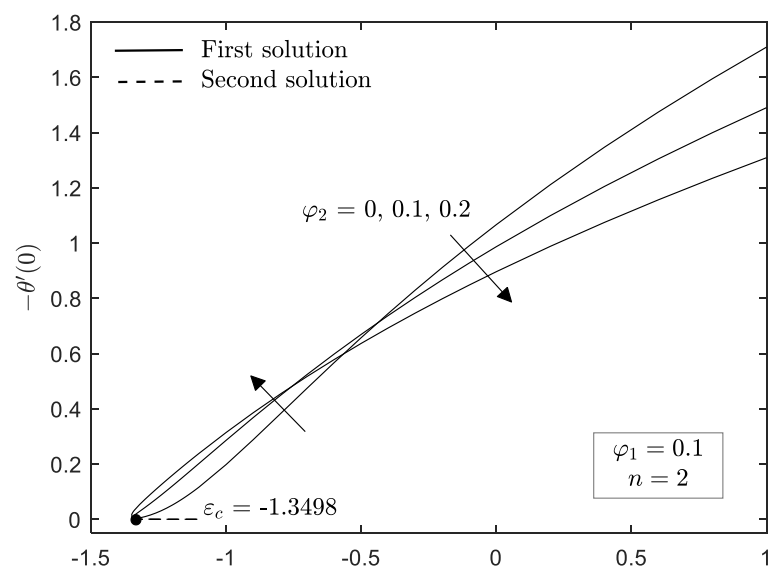

Fig. 5. $-\theta^{\prime}(0)$ with $\varepsilon$ for different $\varphi_{2}$

Figure 6 - 9 present the effect of nonlinear parameter $n$ on the dimensionless velocity $f^{\prime}(\eta)$ and temperature $\theta(\eta)$ profiles, reduced skin friction $f^{\prime \prime}(0)$ and heat transfer $-\theta^{\prime}(0)$ when $\varphi_{1}=\varphi_{2}=0.1$. The dual nature of velocity and temperature profiles is noted. From Figure 6 , it is noticed that as nonlinear $n$ increases, $f^{\prime}(\eta)$ increase within the momentum boundary layer for both solutions. However, $\theta(\eta)$ decrease within the thermal boundary layer in first solution while it increases with increasing nonlinear $n$ for second solution as illustrates in Figure 7. It can be clearly seen from Figure 8 and 9 that with the strengthen value in nonlinear parameter $n$, the range of similarity solution is expanding. The same observation is seen for the existence of duality in these figures and no solution when the values of $\varepsilon$ exceed its critical value, $\varepsilon_{c}$. The critical values for $n=1,2$ and 3 are $\varepsilon_{c}=-1.2465,-1.3498$ and -1.3909 . This implies that the increase in $n$ postponing the separation of boundary layer. Yet, it is found that the second solution has a lower magnitude of $f^{\prime \prime}(0)$ and $-\theta^{\prime}(0)$ for a given $\varepsilon$ than the first solution. It is worth noting that the increasing of nonlinear parameter $n$ leads to enhance the value of $f^{\prime \prime}(0)$ and $-\theta^{\prime}(0)$ for hybrid nanofluids. 


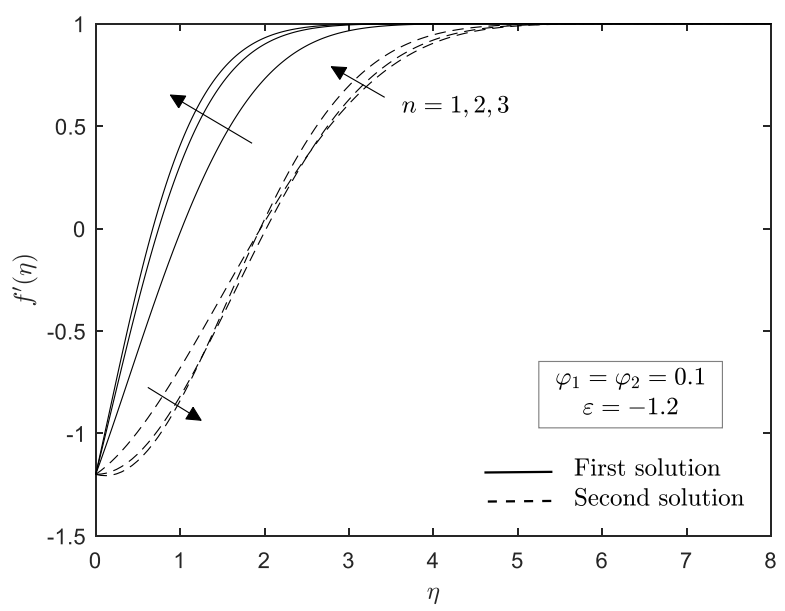

Fig. 6. Velocity profile for different $n$

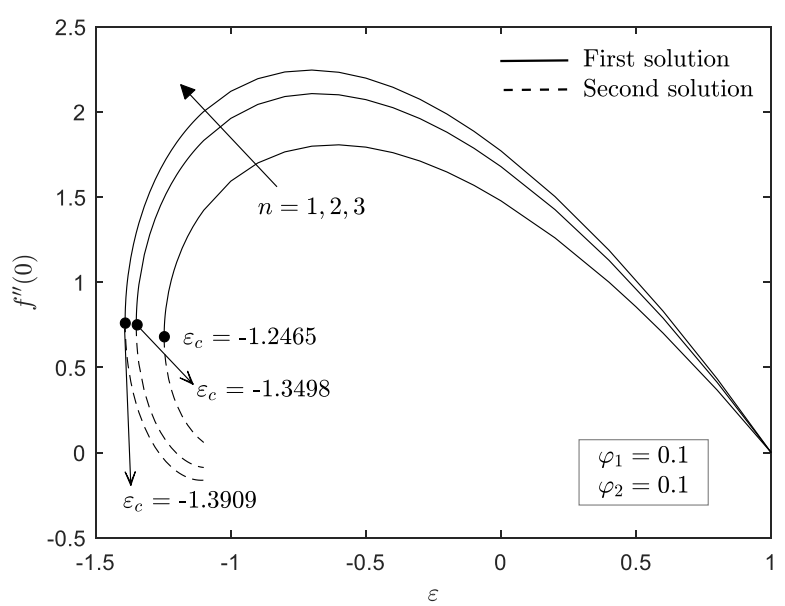

Fig. 8. $f^{\prime \prime}(0)$ with $\varepsilon$ for various $n$

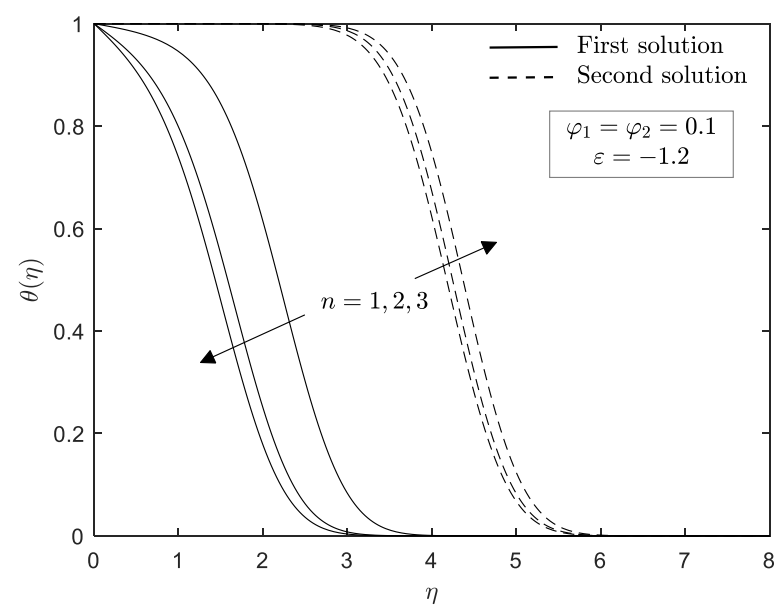

Fig. 7. Temperature profile for different $n$

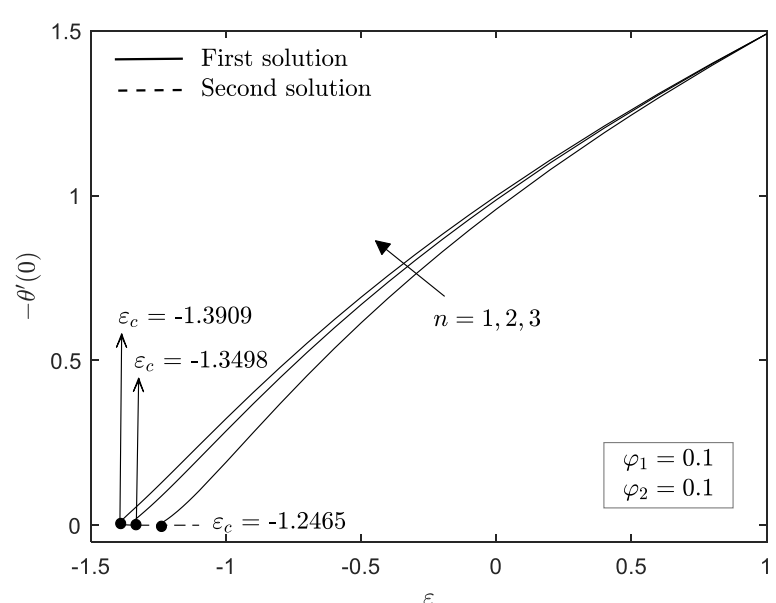

Fig. 9. $-\theta^{\prime}(0)$ with $\varepsilon$ for various $n$

Figure 10 and 11 have been plotted to analyse the variation of local skin friction $\operatorname{Re}_{x}^{1 / 2} C_{f}$ and local Nusselt number $\operatorname{Re}_{x}^{-1 / 2} N u_{x}$ with nanoparticle volume fraction $\left(\varphi_{1}, \varphi_{2}\right)$ for various value of nonlinear parameter $n$ for stretching sheet. It is noted that the $\operatorname{Re}_{x}^{1 / 2} C_{f}$ and $\operatorname{Re}_{x}^{-1 / 2} N u_{x}$ demonstrate an increment as the hybrid nanoparticle $\left(\varphi_{1}, \varphi_{2}\right)$ and nonlinear parameter $n$ increase. It is observed that on using different values of hybrid nanofluid causes a change in $\operatorname{Re}_{x}^{1 / 2} C_{f}$ and $\operatorname{Re}_{x}^{-1 / 2} N u_{x}$. This implies that the addition of nanoparticles in the base fluid plays an important role. Meanwhile, Figure 12 and 13 describe the behaviour of viscous flow, i.e. $\varphi_{1}=\varphi_{2}=0, \mathrm{CuO} /$ water nanofluid, i.e. $\varphi_{1}=0.1, \varphi_{2}=0$ and $\mathrm{Ag}-\mathrm{CuO} /$ water hybrid nanofluid, i.e. $\varphi_{1}=\varphi_{2}=0.1$. For increasing value of nanoparticle $\varphi$, the magnitude of $f^{\prime}(\eta)$ increases, whereas $\theta(\eta)$ decreases. Consequently, the momentum and thermal boundary layer thickness become thinner for hybrid nanofluid compared to the nanofluid, which means that hybrid nanofluid offers higher skin friction and heat transfer rate compared to nanofluid. It is worth mentioning that the boundary conditions (9) are satisfied and met asymptotically for all $f^{\prime}(\eta)$ and $\theta(\eta)$, which support the effectiveness of the numerical outcomes. Also, the thickness of the boundary layer for the second branch found to be thicker than that of the first solution. 


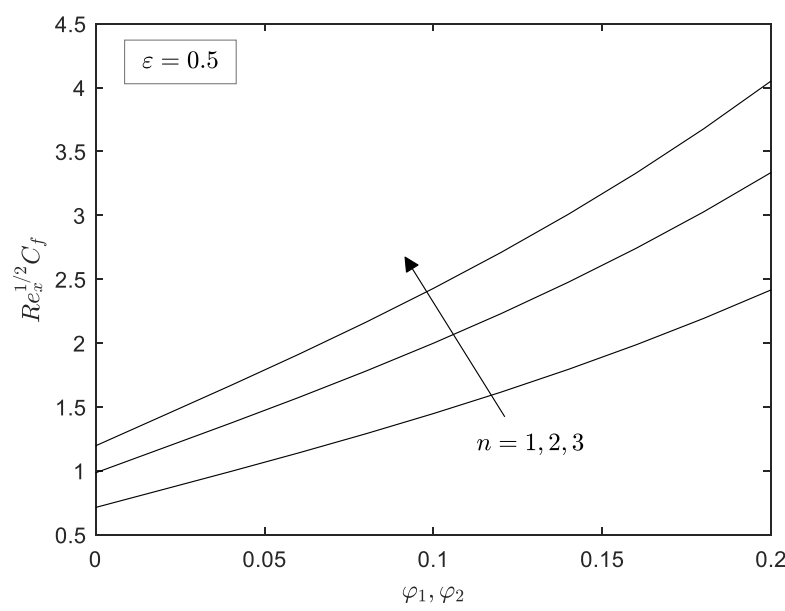

Fig. 10. Local skin friction coefficient for different $n$

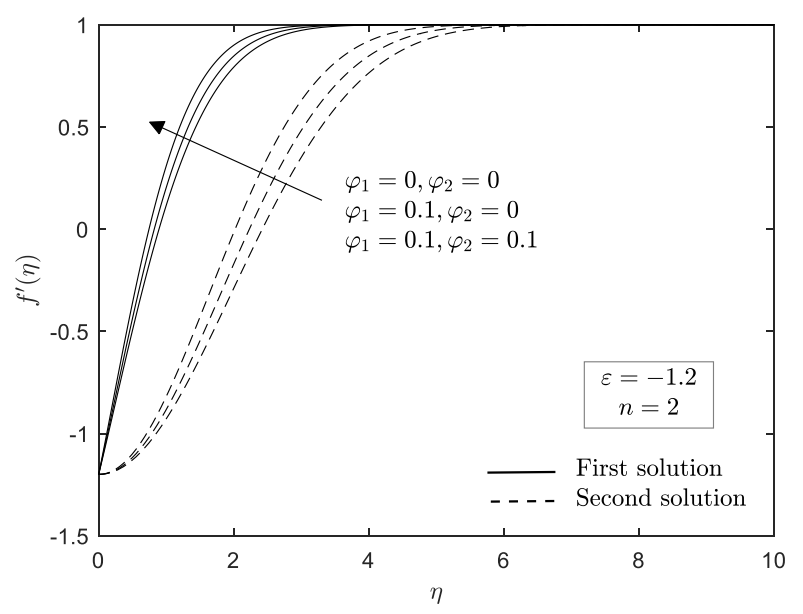

Fig. 12. Velocity profile for various $\varphi$

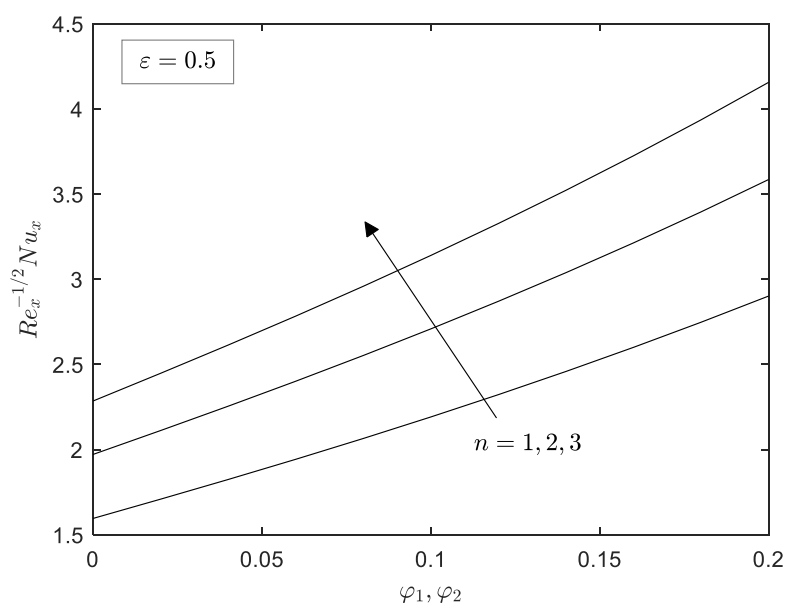

Fig. 11. Local Nusselt number for different $n$

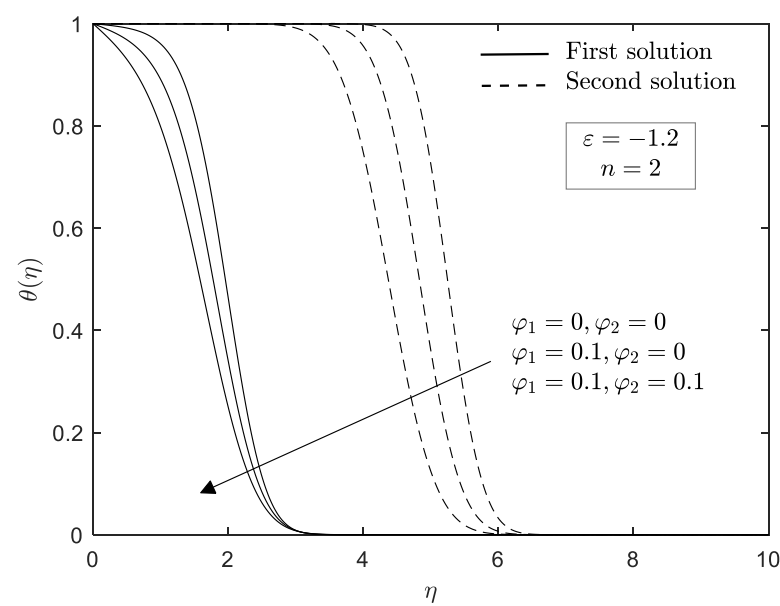

Fig. 13. Temperature profile for various $\varphi$

The duality of the solutions needs to be analysed. Therefore, in order to identify the physical feasibility of the solution, the linearized Eq. (21) and (22) together with the boundary conditions (23) are solved numerically. The stability of the flow can be identified by examining the value of eigenvalue $\gamma$. The flow is in stable mode if the obtained eigenvalues are positive, meanwhile the flow is unstable if the eigenvalues are negative. Table 3 discovers the smallest eigenvalue $\gamma$ for selected range of $\varepsilon$. From the table, it is interesting to observe that the eigenvalue $\gamma$ be close to zero $(\varphi \rightarrow 0)$ as the designated value of $\varepsilon$ near to $\varepsilon_{c}$. It is observed that the eigenvalue $\gamma$ for the first solution ranges within the positive values, while the range of negative value of $\gamma$ is obtained for the second solution. Therefore, it can be declared that the stable flow indicates by the first solution whereas the second solution is unstable. 


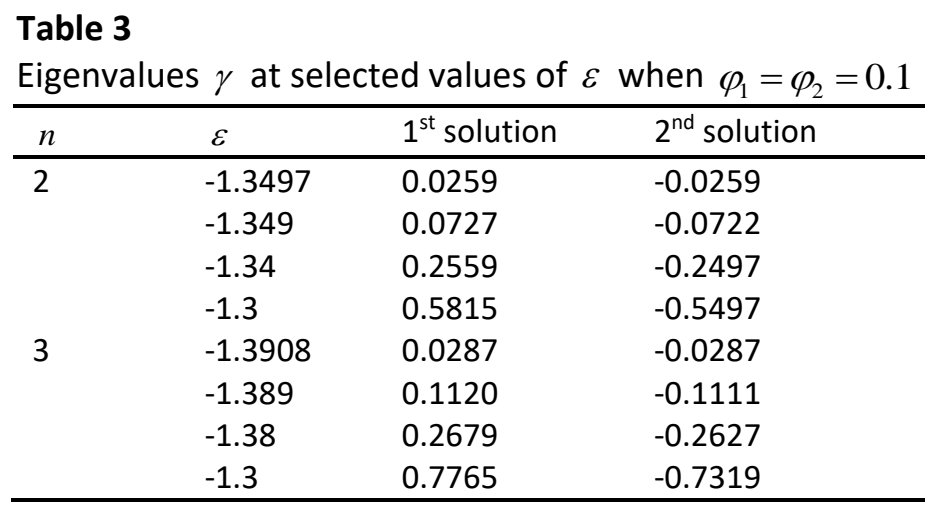

\section{Conclusions}

The problem of stagnation point flow and heat transfer over a nonlinear stretching and shrinking sheet in hybrid nanofluid was studied numerically. Impact of several parameters such as nanoparticle volume fraction $\varphi_{1}, \varphi_{2}$, nonlinear parameter $n$ and stretching/shrinking parameter $\varepsilon$ were presented graphically and discussed. The conclusions of present research are listed as follows

i. Duality exists for a certain limit of shrinking parameter and unique solution are exists for stretching parameter.

ii. The nonlinear parameter delays the boundary layer separation.

iii. The velocity profile increases due to nonlinear parameter $n$ for both solutions. While, the temperature profile decreases for first solution and increase for second solution.

iv. As nanoparticle volume fraction $\varphi_{2}$ increases in shrinking case, the velocity profile increase and temperature profile decrease for both solutions.

v. An increment of nonlinear parameter $n$ and nanoparticle volume fraction $\varphi_{1}, \varphi_{2}$ enhanced the local skin friction and Nusselt number.

vi. The stable flow indicates by the first solution, while second solution represents unstable flow.

\section{Acknowledgement}

The authors gratefully thanks to the Ministry of Higher Education Malaysia for financial support: (FRGS/1/2018/STG06/UPM/02/4/5540155) and MyBrainSc.

\section{References}

[1] Choi, Stephen US, and Jeffrey A. Eastman. Enhancing thermal conductivity of fluids with nanoparticles. No. ANL/MSD/CP-84938; CONF-951135-29. Argonne National Lab., IL (United States), 1995.

[2] Esfe, Mohammad Hemmat, Masoud Afrand, Arash Karimipour, Wei-Mon Yan, and Nima Sina. "An experimental study on thermal conductivity of $\mathrm{MgO}$ nanoparticles suspended in a binary mixture of water and ethylene glycol." International Communications in Heat and Mass Transfer 67 (2015): 173-175. https://doi.org/10.1016/i.icheatmasstransfer.2015.07.009

[3] Suresh, S., K. Venkitaraj, P. Selvakumar, and M. Chandrasekar. "Experimental investigation of mixed convection with synthesis of \$ Al_2O_3-water \$ hybrid nanofluids using two step method and its thermo physical properties." Colloids Surface 8 (2011): 41-48. https://doi.org/10.1016/i.colsurfa.2011.08.005

[4] Momin, Gaffar G. "Experimental investigation of mixed convection with water-Al2O3 \& hybrid nanofluid in inclined tube for laminar flow." Int. J. Sci. Technol. Res 2 (2013): 195-202. 
[5] Devi, S. Suriya Uma, and SP Anjali Devi. "Numerical investigation of three-dimensional hybrid Cu-Al2O3/water nanofluid flow over a stretching sheet with effecting Lorentz force subject to Newtonian heating." Canadian Journal of Physics 94, no. 5 (2016): 490-496.

https://doi.org/10.1139/cip-2015-0799

[6] Hayat, Tanzila, and S. Nadeem. "Heat transfer enhancement with Ag-CuO/water hybrid nanofluid." Results in physics 7 (2017): 2317-2324.

https://doi.org/10.1016/j.rinp.2017.06.034

[7] Manjunatha, S., B. Ammani Kuttan, S. Jayanthi, Ali Chamkha, and B. J. Gireesha. "Heat transfer enhancement in the boundary layer flow of hybrid nanofluids due to variable viscosity and natural convection." Heliyon 5, no. 4 (2019): e01469.

https://doi.org/10.1016/i.heliyon.2019.e01469

[8] Hayat, Tanzila, and S. Nadeem. "An improvement in heat transfer for rotating flow of hybrid nanofluid: a numerical study." Canadian Journal of Physics 96, no. 12 (2018): 1420-1430.

https://doi.org/10.1139/cjp-2017-0801

[9] Farooq, Umer, Muhammad Idrees Afridi, Muhammad Qasim, and D. C. Lu. "Transpiration and viscous dissipation effects on entropy generation in hybrid nanofluid flow over a nonlinear radially stretching disk." Entropy 20, no. 9 (2018): 668. https://doi.org/10.3390/e20090668

[10] Rostami, Mohammadreza Nademi, Saeed Dinarvand, and loan Pop. "Dual solutions for mixed convective stagnation-point flow of an aqueous silica-alumina hybrid nanofluid." Chinese Journal of Physics 56, no. 5 (2018): 2465-2478.

https://doi.org/10.1016/i.cjph.2018.06.013

[11] Yousefi, Mohammad, Saeed Dinarvand, Mohammad Eftekhari Yazdi, and loan Pop. "Stagnation-point flow of an aqueous titania-copper hybrid nanofluid toward a wavy cylinder." International Journal of Numerical Methods for Heat \& Fluid Flow (2018).

https://doi.org/10.1108/HFF-01-2018-0009

[12] Wang, C. Y. "Stagnation flow towards a shrinking sheet." International Journal of Non-Linear Mechanics 43, no. 5 (2008): 377-382.

https://doi.org/10.1016/j.ijnonlinmec.2007.12.021

[13] Bachok, Norfifah, Anuar Ishak, and loan Pop. "Melting heat transfer in boundary layer stagnation-point flow towards a stretching/shrinking sheet." Physics letters A 374, no. 40 (2010): 4075-4079.

https://doi.org/10.1016/i.physleta.2010.08.032

[14] Bhattacharyya, Krishnendu. "Dual solutions in boundary layer stagnation-point flow and mass transfer with chemical reaction past a stretching/shrinking sheet." International Communications in Heat and Mass Transfer 38, no. 7 (2011): 917-922.

https://doi.org/10.1016/j.icheatmasstransfer.2011.04.020

[15] Kameswaran, P. K., M. Narayana, P. Sibanda, and P. V. S. N. Murthy. "Hydromagnetic nanofluid flow due to a stretching or shrinking sheet with viscous dissipation and chemical reaction effects." International Journal of Heat and Mass Transfer 55, no. 25-26 (2012): 7587-7595.

https://doi.org/10.1016/j.ijheatmasstransfer.2012.07.065

[16] Bachok, Norfifah, Anuar Ishak, Roslinda Nazar, and Norazak Senu. "Stagnation-point flow over a permeable stretching/shrinking sheet in a copper-water nanofluid." Boundary Value Problems 2013, no. 1 (2013): 39. https://doi.org/10.1186/1687-2770-2013-39

[17] Pop, Ioan, Kohilavani Naganthran, Roslinda Nazar, and Anuar Ishak. "The effect of vertical throughflow on the boundary layer flow of a nanofluid past a stretching/shrinking sheet." International Journal of Numerical Methods for Heat \& Fluid Flow (2017). https://doi.org/10.1108/HFF-05-2016-0207

[18] Vajravelu, K. "Viscous flow over a nonlinearly stretching sheet." Applied mathematics and computation 124, no. 3 (2001): 281-288.

https://doi.org/10.1016/S0096-3003(00)00062-X

[19] Cortell, Rafael. "Viscous flow and heat transfer over a nonlinearly stretching sheet." Applied Mathematics and Computation 184, no. 2 (2007): 864-873.

https://doi.org/10.1016/i.amc.2006.06.077

[20] Prasad, K. V., K. Vajravelu, and P. S. Datti. "Mixed convection heat transfer over a non-linear stretching surface with variable fluid properties." International Journal of non-linear Mechanics 45, no. 3 (2010): 320-330. https://doi.org/10.1016/i.ijnonlinmec.2009.12.003 
[21] Rana, P., and R. Bhargava. "1.(2012), Flow and heat transfer of a nanofluid over a nonlinear stretching sheet: A numerical study." Communication in Nonlinear Science and Numerical Simulation 17: 212-226.

https://doi.org/10.1016/j.cnsns.2011.05.009

[22] Zaimi, Khairy, Anuar Ishak, and Ioan Pop. "Boundary layer flow and heat transfer over a nonlinearly permeable stretching/shrinking sheet in a nanofluid." Scientific Reports 4 (2014): 4404. https://doi.org/10.1038/srep04404

[23] Fauzi, N. F., S. Ahmad, and I. Pop. "Stagnation point flow and heat transfer over a nonlinear shrinking sheet with slip effects." Alexandria Engineering Journal 54, no. 4 (2015): 929-934. https://doi.org/10.1016/j.aej.2015.08.004

[24] Rana, Puneet, Ruchika Dhanai, and Lokendra Kumar. "Radiative nanofluid flow and heat transfer over a non-linear permeable sheet with slip conditions and variable magnetic field: Dual solutions." Ain Shams Engineering Journal 8 , no. 3 (2017): 341-352. https://doi.org/10.1016/i.asej.2015.08.016

[25] Mabood, Fazle, W. A. Khan, and AI Md Ismail. "MHD boundary layer flow and heat transfer of nanofluids over a nonlinear stretching sheet: a numerical study." Journal of Magnetism and Magnetic Materials 374 (2015): 569-576. https://doi.org/10.1016/i.jmmm.2014.09.013

[26] Ghosh, Sudipta, Swati Mukhopadhyay, and Kuppalapalle Vajravelu. "Dual solutions of slip flow past a nonlinearly shrinking permeable sheet." Alexandria Engineering Journal 55, no. 2 (2016): 1835-1840. https://doi.org/10.1016/i.aej.2016.04.002

[27] Pal, Dulal, and Gopinath Mandal. "Double diffusive magnetohydrodynamic heat and mass transfer of nanofluids over a nonlinear stretching/shrinking sheet with viscous-Ohmic dissipation and thermal radiation." Propulsion and Power Research 6, no. 1 (2017): 58-69. https://doi.org/10.1016/i.jppr.2017.01.003

[28] Daniel, Yahaya Shagaiya, Zainal Abdul Aziz, Zuhaila Ismail, and Faisal Salah. "Effects of slip and convective conditions on MHD flow of nanofluid over a porous nonlinear stretching/shrinking sheet." Australian Journal of Mechanical Engineering 16, no. 3 (2018): 213-229. https://doi.org/10.1080/14484846.2017.1358844

[29] Jamaludin, Anuar, Roslinda Nazar, and Ioan Pop. "Three-dimensional magnetohydrodynamic mixed convection flow of nanofluids over a nonlinearly permeable stretching/shrinking sheet with velocity and thermal slip." Applied Sciences 8, no. 7 (2018): 1128. https://doi.org/10.3390/app8071128

[30] Merkin, J. H. "On dual solutions occurring in mixed convection in a porous medium." Journal of engineering Mathematics 20, no. 2 (1986): 171-179. https://doi.org/10.1007/BF00042775

[31] Weidman, P. D., D. G. Kubitschek, and A. M. J. Davis. "The effect of transpiration on self-similar boundary layer flow over moving surfaces." International journal of engineering science 44, no. 11-12 (2006): 730-737. https://doi.org/10.1016/j.ijengsci.2006.04.005

[32] Merrill, Keith, Matthew Beauchesne, Joseph Previte, Joseph Paullet, and Patrick Weidman. "Final steady flow near a stagnation point on a vertical surface in a porous medium." International journal of heat and mass transfer 49, no. 23-24 (2006): 4681-4686. https://doi.org/10.1016/j.ijheatmasstransfer.2006.02.056

[33] Harris, S. D., D. B. Ingham, and I. Pop. "Mixed convection boundary-layer flow near the stagnation point on a vertical surface in a porous medium: Brinkman model with slip." Transport in Porous Media 77, no. 2 (2009): 267-285. https://doi.org/10.1007/s11242-008-9309-6

[34] Awaludin, Izyan Syazana, Anuar Ishak, and Ioan Pop. "On the stability of MHD boundary layer flow over a stretching/shrinking wedge." Scientific reports 8, no. 1 (2018): 1-8. https://doi.org/10.1038/s41598-018-31777-9

[35] Bakar, Nor Ashikin Abu, Norfifah Bachok, Norihan Md Arifin, and Ioan Pop. "Stability analysis on the flow and heat transfer of nanofluid past a stretching/shrinking cylinder with suction effect." Results in Physics 9 (2018): 13351344.

https://doi.org/10.1016/j.rinp.2018.04.056

[36] Anuar, Nur Syazana, Norfifah Bachok, Norihan Md Arifin, and Haliza Rosali. "Stagnation point flow and heat transfer over an exponentially stretching/shrinking sheet in CNT with homogeneous-heterogeneous reaction: stability analysis." Symmetry 11, no. 4 (2019): 522. https://doi.org/10.3390/sym11040522 
[37] Anuar, Nur Syazana, Norfifah Bachok, Norihan Md Arifin, and Haliza Rosali. "Role of multiple solutions in flow of nanofluids with carbon nanotubes over a vertical permeable moving plate." Alexandria Engineering Journal 59, no. 2 (2020): 763-773. https://doi.org/10.1016/i.aej.2020.02.015

[38] Malvandi, A., F. Hedayati, and D. D. Ganji. "Nanofluid flow on the stagnation point of a permeable non-linearly stretching/shrinking sheet." Alexandria engineering journal 57, no. 4 (2018): 2199-2208. https://doi.org/10.1016/i.aej.2017.08.010

[39] Bachok, Norfifah, and Anuar Ishak. "Similarity solutions for the stagnation-point flow and heat transfer over a nonlinearly stretching/shrinking sheet." Sains Malaysiana 40, no. 11 (2011): 1297-1300.

[40] Oztop, Hakan F., and Eiyad Abu-Nada. "Numerical study of natural convection in partially heated rectangular enclosures filled with nanofluids." International journal of heat and fluid flow 29, no. 5 (2008): 1326-1336. https://doi.org/10.1016/i.ijheatfluidflow.2008.04.009 